\title{
AGILE MANUFACTURING THROUGH INVENTORY MANAGEMENT
}

\author{
Rudy Santosa Sudirga ${ }^{1)}$, Filscha Nurprihatin ${ }^{2)}$, Glisina Dwinoor Rembulan ${ }^{3)}$, Yustinus \\ Yuniarto ${ }^{4)}$ \\ Program Studi Manajemen, Universitas Bunda Mulia \\ Program Studi Teknik Industri, Sampoerna University \\ Program Studi Teknik Industri, Universitas Bunda Mulia \\ Program Studi Manajemen, Universitas Bunda Mulia
}

Diterima 22 Juni 2021 / Disetujui 30 Juni 2021

\begin{abstract}
Inventory management is a systematic approach to sourcing, storing, and selling inventory both raw materials (components) and finished goods (products). In business terms, inventory management means the right stock, at the right levels, in the right place, at the right time, and at the right cost as well as price. Inventory management refers to the process of ordering, storing and using a company's inventory. This includes the management of raw materials, components and finished products, as well as warehousing and processing such items. For companies with complex supply chains and manufacturing processes, balancing the risks of inventory gluts and shortages is especially difficult. At the same time, inventory can be thought of as a liability (if not in an accounting sense). A large inventory carries the risk of spoilage, theft, damage or shifts in demand. Inventory must be insured, and if it is not sold in time it may have to be disposed of at clearance prices or simply destroyed. For these reasons, inventory management is important for businesses of any size. Knowing when to restock inventory, what amounts to purchase or produce, what price to pay as well as when to sell and at what pric can easily become complex decisions. Small businesses will often keep track of stock manually and determine the reorder points and quantities using Excel formulas. Larger businesses will use specialized enterprise resource planning (ERP) software.
\end{abstract}

Keywords: Inventory, Right Stock, Right Cost.

\begin{abstract}
ABSTRAK
Manajemen persediaan adalah pendekatan sistematis untuk mencari, menyimpan, dan menjual persediaan baik bahan mentah (komponen) dan barang jadi (produk). Dalam istilah bisnis, manajemen persediaan berarti persediaan yang tepat, pada tingkat yang tepat, di tempat yang tepat, pada waktu yang tepat, dan pada biaya serta harga yang tepat. Manajemen persediaan mengacu pada proses pemesanan, penyimpanan dan penggunaan persediaan perusahaan. Ini termasuk pengelolaan bahan baku, komponen dan produk jadi, serta pergudangan dan pengolahan barang-barang tersebut. Untuk perusahaan dengan rantai pasokan dan proses manufaktur yang kompleks, menyeimbangkan risiko kelebihan dan kekurangan persediaan sangat sulit. Pada saat yang sama, persediaan dapat dianggap sebagai kewajiban (jika tidak dalam pengertian akuntansi). Persediaan yang besar membawa risiko pembusukan, pencurian, kerusakan, atau pergeseran permintaan. Persediaan harus diasuransikan, dan jika tidak dijual tepat waktu, persediaan tersebut mungkin harus dibuang dengan harga bebas atau dimusnahkan begitu saja. Untuk alasan ini, manajemen persediaan penting untuk bisnis dari berbagai ukuran. Mengetahui kapan harus mengisi kembali persediaan, berapa jumlah yang harus dibeli atau diproduksi, berapa harga yang harus dibayar serta kapan harus menjual dan berapa harganya dapat dengan mudah menjadi keputusan yang rumit. Usaha kecil akan sering melacak stok secara manual dan menentukan titik pemesanan ulang dan jumlah menggunakan rumus Excel. Bisnis yang lebih besar akan menggunakan perangkat lunak perencanaan sumber daya perusahaan (ERP).
\end{abstract}

Kata Kunci: Persediaan, Persediaan Sesuai, Biaya Sesuai.

*Korespondensi Penulis:
E-mail: rudysudirga@yahoo.com 


\section{PENDAHULUAN}

Menurut Heizer \& Render (2017), Inventory Management atau manajemen persediaan adalah pendekatan sistematis untuk mencari, menyimpan, dan menjual persediaan baik bahan mentah (komponen) dan barang jadi (produk). Dalam istilah bisnis, manajemen persediaan berarti persediaan yang tepat, pada tingkat yang tepat, di tempat yang tepat, pada waktu yang tepat, dan pada biaya serta harga yang tepat.

Menurut Krajewski et.al. (2016), Manajemen persediaan adalah perencanaan dan pengendalian persediaan untuk memenuhi prioritas kompetitif organisasi. Manajemen persediaan yang efektif sangat penting untuk mewujudkan potensi penuh dari setiap rantai nilai. Manajemen persediaan membutuhkan informasi tentang permintaan yang diharapkan, jumlah di tangan dan jumlah pesanan untuk setiap item yang ditebar di semua lokasi. Waktu yang tepat dan ukuran jumlah pemesanan ulang juga harus ditentukan.

Menurut Heizer \& Render (2017), di dalam mengelola manajemen persediaan, perusahaan harus mneyediakan persediaan produk atau barang yang cukup untuk memuaskan pelanggan, akan tetapi jika persediaan perusahaan terlalu besar, maka asset perusahaan dalam bentuk uang cash akan tertanam lama di persediaan sebelum dapat dijual menjadi uang kembali, dan hal ini akan mengakibatkan kerugian bagi perusahaan. Akan tetapi jika persedian produk atau barang terlalu kecil, maka perusahaan juga akan mernderita kerugian karena pelanggan akan merasa tidak puas karena terbatasnya produk yang ada di pasaran, sehingga akan mengalami kehilangan penjualan yang nantinya akan mengakibatkan kerugian juga bagi perusahaan. Oleh karena itu perusahaan harus mencari suatu titik yang paling optimal dari persediaan produk atau barang di perusahaan agar persediaan memenuhi kriteria supply and demand dan perusahaan mendapatkan biaya yang paling optimal dari uang yang tertanam di persediaan perusahaan. Di dalam menemukan titik optimal persediaan dan biaya yang paling optimal bagi perusahaan dalam menyediakan persediaan, perusahaan akan memakai manajemen persediaan yaitu memakai prinsip economic order quantity dalam menentukan titik optimal persediaan dan kapan harus melakukan order kembali dari bahan baku perusahaan, dan juga agar perusahaan dapat mendapatkan biaya yang paling optimal.

Menurut Stevenson (2014), funsgi manajemen persediaan sangat penting bagi perusahaan. Hal ini karena fungsi dari aktivitas tersebut cukup beragam. Berikut adalah fungsi dari manajemen persediaan:

1. Mengantisipasi kekurangan persediaan

Hal ini harus diperhatikan terutama bagi perusahaan yang berfokus dalam memproduksi barang. Meskipun pada umumnya supply bahan baku memang sudah pasti datang sesuai jadwal, langkah antisipasi tetap penting untuk dilakukan. Untuk berjagajaga jika seumpama persediaan datang terlambat dan akan berpotensi mengganggu proses produksi.

2. Mengantisipasi pesanan persediaan ternyata tidak sesuai dengan kebutuhan

Kondisi seperti pesanan yang tidak sesuai mungkin jarang terjadi. Namun bukan tidak mungkin bisa terjadi. Perusahaan selalu harus memastikan pesanan persediaan yang diterima apakah sudah sesuai yang dibutuhkan untuk proses produksi.

3. Berjaga-jaga jika persediaan yang dibutuhkan ternyata tidak ada di pasaran

Fungsi utama dilakukannya manajemen persediaan adalah untuk memastikan persediaan bahan baku selalu tersedia. Langkah ini untuk mengantisipasi jika bahan baku yang biasa digunakan tidak ditemukan di pasaran. Bisa karena stok habis, atau hal lainnya.

Menurut Chopra (2014), tipe persediaan ada empat, yaitu: (1) persediaan bahan baku, (2) persediaan produk dalam proses atau produk setengah jadi, (3) persediaan produk jadi, (4) persediaan sparepart peralatan proses produksi untuk kesinambungan proses produksi. Beberapa perusahaan, seperti produsen, perlu mengelola berbagai persediaan dalam klasifikasi yang berbeda, sehingga pelacakan persediaan yang efisien menjadi suatu keharusan. Untuk mengelola persediaan secara efektif, solusi jumlah (quantity), dan tipe serta pelacakan persediaan dilakukan dengan menggunakan system inventory application atau aplikasi software manajemen persediaan. 
Menurut Hillier (2018), dalam era modern sekarang ini cara menghitung economic order quantity harus disesuaikan dengan keadaan demand (permintaan) di pasar dan perusahaan - perusahaan besar sudah banyak yang menggunakan software inventory management untuk menentukan economic order quantity, dengan cara menentukan holding cost dan order cost secara berkala sesuai dengan keadaan internal dan eksternal perusahaan saat melakukan persediaan. Untuk hasil yang lebih tepat maka dilakukan perhitungan demand per satuan waktu, holding cost dan order cost secara berkala agar bisa didapatkan economic order quantity yang lebih mendekati kenyataan. Perusahaan harus terus memonitor hasilnya agar bila didapatkan penyimpangan, bisa secara cepat disesuaikan dengan keadaan naik turunnya demand atau terjadinya perubahan faktor internal maupun eksternal perusahaan.

\section{METODE PENELITIAN}

Metode pemberian manajemen persediaan kepada para manajer dan supervisor di perusahaan manufacturing, distributor, maupun retail store dan perusahaan lainnya yang memproduksi suatu produk dengan menyiapkan suatu manajemen persediaan ini diberikan secara semiloka daring dengan melakukan presentasi dan tanya jawab antara peserta semiloka pada tanggal 8 Mei 2021. Metode semiloka daring ini dipilih mengingat keadaan pandemi saat ini dan tidak memungkinkan bagi Universitas Bunda Mulia untuk melakukan pemberian materi manajemen persediaan secara tatap muka dengan para peserta pelatihan. Pada akhir presentasi juga diberikan kesempatan bagi para peserta pelatihan untuk bertanya kepada presenter dan presenter Rudy Santosa Sudirga menjawab semua pertanyaan peserta pelatihan dengan sangat bagus, dan
Input data ke software juga harus dilakukan secara berkala.

Pengabdian kepada masyarakat ini kami berikan berupa semiloka kepada para manajer dan supervisor di perusahaan manufacturing, distributor, maupun retail store dan perusahaan lainnya yang memproduksi suatu produk dengan menyiapkan suatu manajemen persediaan, dengan maksud dan tujuan agar para manajer dan supervisor di perusahaan tersebut dapat menanggulangi secara lebih baik persediaan di perusahaannya dan agar dapat lebih produktif lagi dalam mengelola persediaan perusahaan. Selain itu semiloka ini juga membantu memberikan hasil yang lebih baik dalam mengelola biaya yang paling optimal dan efisien bagi pengelolaan biaya persediaan di perusahaan.

*Korespondensi Penulis:

E-mail: rudysudirga@yahoo.com mendapatkan respon yang baik dari seluruh peserta pelatihan. Presenter juga memberikan contoh-contoh nyata dalam manajemen persediaan secara umum maupun manajemen persediaan di dalam proses produksi yang ada hubungannya dengan mengelola persediaan dan menentukan biaya yang paling optimal bagi tersedianya persediaan. Juga dilakukan pemaparan mengenai pengunaan software seperti SAP dalam era modern ini. Selesai sesi pelatihan juga dibagikan kuesioner secara daring kepada para peserta pelatihan yang berisi pertanyaan mengenai kepuasan pelatihan, kepuasan hasil tanya jawab, dan usulan pelatihan serta umpan balik pelatihan. Hasil kepuasan pelatihan mendapatkan respon yang sangat baik dan antusias dari para peserta pelatihan.

Versi Online: http://journal.ubm.ac.id/ Hasil Penelitian 


\section{HASIL DAN PEMBAHASAN}

Dalam pembahasan manajemen persediaan kita mengacu pada Heizer \& Render (2017) yang menjelaskan mengenai faktor-faktor yang menjadi penentu efisiensi persediaan, diantaranya adalah sebagai berikut:

Faktor - faktor penentu manajemen persediaan meliputi:

(1) Biaya penyimpanan (holding cost), adalah biaya untuk penyimpan persediaan selama satu tahun, dan dinyatakan dalam rupiah/unit/tahun.

Biaya penyimpanan akan menjadi lebih besar jika jumlah persediaan di perusahaan juga menjadi lebih besar. Jadi biaya penyimpanan sesuai dengan besarnya persediaan yang akan kita simpan di gudang, makin besar jumlah persediaan makin besar pula biaya penyimpanan, dan makin kecil jumlah persediaan makin kecil pula biaya penyimpanan.

(2) Biaya satu kali melakukan pembelian/order (order cost). Biaya satu kali melakukan pembelian adalah biaya yang timbul saat perusahaan melakukan pembelian dalam jumlah tertentu ke pemasok barang atau produk dan dinyatakan dalam rupiah/satu kali order. Bilamana kebutuhan dalam satu tahun (demand) dibagi dengan jumlah kuantitas dalam satu kali order, maka akan didapatkan jumlah pembelian/order. Jumlah pembelian/order ini dikalikan dengan biaya satu kali melakukan pembelian/order (order cost). Oleh karena itu jika perusahaan pada saat melakukan pembelian/order melakukan dalam jumlah yang besar kuantitasnya, maka jumlah pembelian/order dalam kurun waktu satu tahun akan berkurang menjadi lebih kecil. Oleh karena itu, semakin besar jumlah kuantitas dalam satu kali pembelian/order, maka akan semakin kecil perusahaan melakukan pembelian/order dalam kurun waktu satu tahun. Sehingga dapat disimpulkan bahwa semakin besar jumlah kuantitas dalam satu kali pembelian/order, maka semakin kecil pula total biaya pembelian (order cost) bagi perusahaan.

(3) Kebutuhan per tahun (Demand/year). Kebutuhan bahan baku atau produk untuk dijual kepada pelanggan merupakan faktor penting yang menentukan economic order quantity (EOQ). Semakin besar kebutuhan per tahun atau demand/year, maka jumlah ekonomis pembelian bahan baku atau produk (economic order quantity) akan meningkat, karena di dalam rumus economic order quantity, demand berbanding lurus dengan economic order quantity. Demand di dalam rumus economic order quantity adalah demand yang konstan dan tidak berubah-ubah atau sangat sedikit mengalami perubahan sehingga dapat dianggap konstan. Dalam menentukan demand harus dilihat faktor historis perusahaan pada masa 1 atau 2 tahun sebelumnya, sehingga kenaikan demand yang akan datang dapat ditentukan berdasarkan historis demand perusahaan pada masa sebelumnya.

(4) Waktu yang diperlukan dari saat order bahan baku atau produk sampai bahan baku atau produk tersebut diterima di gudang disebut sebagai lead time. Lead time sangat menentukan reorder point. Reorder point adalah saat jumlah persediaan menurun ke 
suatu jumlah atau titik tertentu, maka perusahaan harus melakukan order kembali atau pembelian kembali bahan baku atau produk yang dibutuhkan agar tidak terjadi kehabisan persediaan. Reorder point (jumlah persediaan bahan baku atau produk di persedian saat perusahaan harus melakukan order kembali atau pembelian kembali bahan baku atau produk) sangat ditentukan oleh lead time, semakin pendek lead time semakin kecil pula reorder point, sedangkan semakin panjang lead time maka semakin besar pula reorder point. Lead time biasanya dinyatakan dalam jumlah hari kerja yang dibutuhkan dari saat order bahan baku atau produk sampai bahan baku atau produk tersebut diterima di gudang. Lead time yang pendek lebih menguntungkan bagi perusahaan dibandingkan lead time yang panjang.

(5) Harga pembelian (P). Harga pembelian dimasukkan juga sebagai salah satu faktor untuk melakukan order atau pembelian bahan baku dan produk. Harga pembelian yang rendah juga bisa menjadi salah satu faktor untuk melakukan persediaan dalam jumlah yang lebih banyak, akan tetapi tetap harus mengacu pada rumus economic order quantity (jumlah ekonomis pembelian bahan baku atau produk). Faktor harga pembelian biasanya dipakai oleh perusahaan dalam menentukan total biaya yang harus dikeluarkan oleh perusahaan dalam waktu satu tahun pembelian bahan baku atau produk, dan perusahaan biasanya menginginkan total biaya yang paling rendah.

(6) EOQ (Economic Order Quantity $=$ jumlah ekonomis pembelian bahan baku atau produk), yaitu jumlah yang paling ekonomis saat prusahaan ingin melakukan order atau pembelian bahan baku atau produk. Economic order quantity ini harus diikuti oleh perusahaan dengan syarat demand adalah konstan dan lead time juga konstan serta penjualan dan produksi dalam keadaan berkesinambungan. Jika perusahaan mengikuti dan memakai economic order quantity, maka perusahaan akan mendapatkan dan melakukan jumlah order yang paling optimal dan juga mendapatkan total biaya yang paling optimal pula, sehingga dapat disimpulkan bahwa perusahaan akan mendapatkan hasil yang paling optimal dan bagus dengan keputusan yang didasarkan pada economic order quantity ini.

Menurut Krajewski et.al. (2013), terdapat banyak faktor yang menjadi pemicu kelebihan persediaan dalam jumlah yang besar, baik dari faktor eksternal maupun faktor internal, maupun faktor ekonomi yang tidak terduga sebelumnya.

Faktor - faktor yang menjadi pemicu kelebihan persediaan dalam jumlah yang besar adalah sebagai berikut:

(1) Perusahaan mendapatkan harga diskon dari pemasok bahan baku atau produk, sehingga perusahaan ingin membeli dalam jumlah yang besar. Hal ini akan memicu perusahaan atau pembeli untuk membeli bahan baku atau produk dalam jumlah yang besar yang berakibat jumlah persediaan perusahaan menjadi lebih besar dibandingkan economic order quantity.

(2) Terjadinya suatu keadaan inflasi sehingga terjadi penjualan yang sangat besar karena adanya pembelian dari pelanggan dalam jumlah yang besar (rush). Hal ini akan memicu perusahaan atau pembeli untuk membeli bahan 
baku atau produk dalam jumlah yang besar yang berakibat jumlah persediaan perusahaan menjadi lebih besar dibandingkan economic order quantity.

(3) Terjadinya suatu keadaan dimana kurs negara pembeli jatuh terhadap kurs negara pemasok/penjual. Hal ini akan memicu perusahaan atau pembeli untuk membeli bahan baku atau produk dalam jumlah yang besar yang berakibat jumlah persediaan perusahaan menjadi lebih besar dibandingkan economic order quantity.

(4) Terjadinya trend penjualan yang sangat besar karena memang demand nya sangat besar akhirakhir ini. Hal ini akan memicu perusahaan atau pembeli untuk membeli bahan baku atau produk dalam jumlah yang besar yang berakibat jumlah persediaan perusahaan menjadi lebih besar dibandingkan economic order quantity.

(5) Perusahaan memang ingin membeli bahan baku atau produk dalam jumlah besar, karena sudah mengetahui bahwa akan ada kenaikan harga dari bahan baku atau produk yang akan dipakai dalam proses produksi atau penjualan. Hal ini akan memicu perusahaan atau pembeli untuk membeli bahan baku atau produk dalam jumlah yang besar yang berakibat jumlah persediaan perusahaan menjadi lebih besar dibandingkan economic order quantity.

Dari penjelasan faktor-faktor yang menajadi pemicu kelebihan persediaan dalam jumlah besar, para peserta pelatihan diminta untuk melakukan dan menanyakan hal-hal yang menjadikan perhatian dari para peserta seminar di perusahaan tempat bekerja, dan didapatkan hasil sebagai berikut:

(1) Pertanyaan mengenai cara menentukan holding cost dan order cost di perusahaan distributor.

(2) Estimasi menentukan biaya holding cost dan order cost untuk menentukan economic order quantity.

(3) Inventory atau persediaan di perusahaannya cukup besar dan sudah menerapkan SAP/MRP serta Bill of Material, akan tetapi masih juga kadang mengalami kekurangan persediaan.

(4) Bila holding cost berubah dan order cost tetap, apakah model SAP harus dilakukan penyesuaian.

Dari hasil pertanyaan di atas, penulis menjawab semua pertanyaan peserta pelatihan dengan jawaban sebagai beikut:

(1) Untuk perusahaan distributor memang persediaan perusahaan sangat tinggi karena sebagai perusahaan distributor harus secara terus menerus menyediakan persediaan dari berbagai produk yang akan dijual atau disalurkan. Disebabkan karena banyaknya produk di persediaan dan karena penjualan berjalan secara berkesinambungan, maka dianjurkan kepada perusahaan distributor tersebut untuk memakai software SAP atau sejenisnya, agar software SAP atau sejenisnya bisa membantu perusahaan distributor tersebut menentukan holding cost dan order cost dari berbagai macam produk yang terdapat di perusahaan distributor tersebut.

(2) Estimasi menentukan biaya holding cost dan order cost adalah dengan cara menentukan perkiraan biaya penyimpanan produk dalam waktu satu tahun. Dari biaya 
penyimpanan selama satu tahun dikalikan dengan ratarata persediaan selama satu tahun akan didapatkan total holding cost. Sedangkan order cost ditentukan dengan cara memperkirakan biaya yang terjadi pada saat kita melakukan order, yaitu dengan cara menghitung demand dibagi dengan jumlah order quantity (jumlah pembelian) dikalikan dengan estimasi biaya untuk satu kali melakukan order ke pemasok bahan baku atau produk tersebut.

(3) Inventory atau persediaan masih kadang kurang walaupun sudah memakai software SAP. Disarankan agar memasukkan data input planning yang benar kedalam software SAP, sebab kesalahan input data planning kedalam software SAP akan membuat software tersebut meramalkan yang tidak sesuai dengan kebutuhan atau demand perusahaan atau demand pelanggan. Akan tetapi ada kemungkinan memang input data planning sudah benar, akan tetapi memang ada lonjakan pembelian dari pelanggan perusahaan secara besar secara berkala, oleh karena itu penulis menyarankan untuk menambahkan safety stock di persediaan perusahaan.

(4) Bila holding cost berubah, maka perusahaan harus menyesuaikan pula perubahan holding cost dengan cara mengubah holding cost di software SAP, agar software SAP dapat meramalkan economic order quantity secara tepat dan lebih baik. Bila perusahaan menyewa gudang, perubahan holding cost biasanya disebabkan adanya kenaikan harga sewa gudang, biaya sewa forklift, dan lain lain. Dan bila gudang dimiliki sendiri oleh perusahaan, maka kenaikan harga listrik atau kenaikan upah karyawan gudang akan menyebabkan pula kenaikan holding cost perusahaan.

Hasil pelatihan Agile Manufacturing Through Inventory Management ini mendapatkan respon yang sangat baik dan antusias dari para peserta pelatihan. Hasil tanya jawab juga mendapatkan respon yang sangat baik dari para peserta pelatihan dan hasil umpan balik para peserta pelatihan dapat di lihat dari tabel di bawah ini:

Tabel 1. Umpan Balik Peserta Pelatihan

\begin{tabular}{|c|c|c|c|c|}
\hline Nama Lengkap & Asal Institusi & Jabatan & $\begin{array}{l}\text { Manfaat } \\
\text { Kegiatan } \\
\text { bagi } \\
\text { Peserta }\end{array}$ & $\begin{array}{l}\text { Relevansi } \\
\text { Materi yang } \\
\text { Disampaikan } \\
\text { dengan } \\
\text { Tujuan } \\
\text { Kegiatan }\end{array}$ \\
\hline $\begin{array}{l}\text { Muhammad Kholil Qolbi, } \\
\text { Hons }\end{array}$ & $\begin{array}{l}\text { SMKN } 1 \text { SUKAPURA } \\
\text { Universitas Pasundan }\end{array}$ & Guru & 4 & 4 \\
\hline Regina Sucianti & $\begin{array}{l}\text { Bandung } \\
\text { Universitas Atma Jaya }\end{array}$ & Mahasiswa & 4 & 4 \\
\hline B. Laksito Purnomo & $\begin{array}{l}\text { Yogyakarta } \\
\text { Universitas Amikom }\end{array}$ & Dosen & 3 & 3 \\
\hline Harry Zulkifli & Purwokerto & Mahasiswa & 3 & 4 \\
\hline
\end{tabular}




\begin{tabular}{|c|c|}
\hline Patricia Inez Tantio & Universitas Bunda Mulia \\
\hline Febiola Wulandari & Universitas Bunda Mulia \\
\hline AGUS SULISTIYONO & PT EURO DESIGN \\
\hline Verensia & UBM \\
\hline RICHALD & Universitas Bunda Mulia \\
\hline Hadi Cahyono & $\begin{array}{l}\text { STMIK STIKOM INDONESIA } \\
\text { PT. Sumatera Prima }\end{array}$ \\
\hline Ricky Adrian Bessie & Fibreboard \\
\hline Dewi llyana & SMK NEGERI 1 TANJUNG \\
\hline Laurentius Wiragni Sanjaya & $\mathrm{KAI}$ \\
\hline Muhammad makinun amin & Upn veteran jatim \\
\hline $\begin{array}{l}\text { Achmad Mudjadid } \\
\text { TESALONIKA PUTRI }\end{array}$ & PT Putra Kalimantan Terigas \\
\hline NUGROHO & IIK BHAKTI WIYATA KEDIRI \\
\hline I Dewa Made Pranata Wiana & Biro PBJ Setda Provinsi Bali \\
\hline Rio Sanjaya & SMK N 3 Pontianak \\
\hline
\end{tabular}

$\begin{array}{lll}\text { Mahasiswa } & 4 & 4 \\ \text { Mahasiswa } & 4 & 4 \\ \text { Supervisor } & 4 & 3 \\ \text { Mahasiswa } & 4 & 4 \\ \text { Mahasiswa } & 3 & 3 \\ \text { Mahasiswa } & 3 & 3 \\ \text { Supervisor } & 3 & 4 \\ \text { Pelajar } & & \\ \text { SMP/SMA } & 4 & 4 \\ \text { Manajer } & 4 & 4 \\ \text { Mahasiswa } & 3 & 3 \\ \text { Founder/ } & & 4 \\ \text { Owner } & 4 & 4 \\ \text { Mahasiswa } & 4 & 4 \\ \text { Staff } & 4 & \\ \text { Pelajar } & & \\ \text { SMP/SMA } & 4 & \end{array}$

\section{SIMPULAN}

Kesimpulan yang didapat dari para peserta pelatihan Agile Manufacturing Through Inventory Management adalah sebagai berikut:

1. Para peserta pelatihan merasa presentasi dengan topik Agile Manufacturing Through Inventory Management sangat bagus dan sangat berguna untuk mengatasi masalah inventory.

2. Para peserta pelatihan dengan topik Agile Manufacturing Through Inventory Management merasa sangat puas dengan hasil yang didapatkan dari pelatihan ini..

3. Para peserta pelatihan dengan topik Agile Manufacturing Through Inventory Management merasa topik yang dibawakan sangat menarik dan ingin mengulangi untuk mendapatkan topik sama yang lebih luas pada kesempatan berikutnya.
4. Para peserta pelatihan dengan topik Agile Manufacturing Through Inventory Management merasa kemampuan atau penguasaan materi dan kemampuan dalam menyampaikan materi sudah sangat bagus dan berguna dalam mengatasi masalah inventory di perusahaan tempat bekerja.

5. Para peserta pelatihan dengan topik Agile Manufacturing Through Inventory Management merasa bahwa kemampuan presenter sudah sangat bagus dan sudah menggunakan metode yang tepat dalam penyampaian materi pelatihan.

6. Para peserta pelatihan dengan topik Agile Manufacturing Through Inventory Management merasa bahwa kemampuan menciptakan suasana yang mendukung selama semiloka, saat pembawaan materi, dan saat tanya jawab sudah sangat bagus. 


\section{DAFTAR PUSTAKA}

Chopra, S., Meindl, P., (2014). Supply Chain Management: Strategy, Planning and Operation, $6^{\text {th }}$ edition, Pearson Education Limited, USA.

Heizer, J., Render, B., Munson, C., (2017). Operations Management, Sustainability and Supply Chain Management, 12 global edition, Pearson Education Limited, USA.

Hiillier, F., Hillier, M., (2018). Introduction to Management Science: A Modeling and Case Studies Approach with Spreadsheets, $6^{\text {th }}$ edition, McGraw-Hill Education, USA.
Krajewski, L., J., et. al. (2013). Operations Management, Process and Supply Chains, $10^{\text {th }}$ global edition, Pearson Education Limited, USA.

Krajewski, L., J., et. al. (2016). Operations Management, Process and Supply Chains, $11^{\text {th }}$ global edition, Pearson Education Limited, USA.

Stevenson, W., J., Chuong, S., C., (2014). Operations Management, $2^{\text {nd }}$ asia global edition, McGraw-Hill Education, Singapore.

Taylor, B. W., (2013). Introducttion to Management Science, $11^{\text {th }}$ edition, Pearson Education Limited, USA. 